Case Report

\title{
Treatment of Complete Anal Stricture after Diverting Colostomy for Fournier's Gangrene
}

\author{
Kenji Okumura, ${ }^{1}$ Tadao Kubota, ${ }^{1}$ Kazuhiro Nishida, ${ }^{2}$ \\ Alan Kawarai Lefor, ${ }^{1,3}$ and Ken Mizokami ${ }^{1}$ \\ ${ }^{1}$ Department of Surgery, Tokyo Bay Urayasu-Ichikawa Medical Center (Noguchi Memorial Institution Hospital), Urayasu, Japan \\ ${ }^{2}$ Department of Surgery, Uwamachi General Hospital, Yokosuka, Japan \\ ${ }^{3}$ Department of Surgery, Jichi Medical University, Tochigi, Japan
}

Correspondence should be addressed to Kenji Okumura; kenjioku620@gmail.com

Received 21 July 2016; Accepted 5 January 2017; Published 31 January 2017

Academic Editor: Imran Hassan

Copyright (c) 2017 Kenji Okumura et al. This is an open access article distributed under the Creative Commons Attribution License, which permits unrestricted use, distribution, and reproduction in any medium, provided the original work is properly cited.

\begin{abstract}
Background. Anal stenosis is a rare but serious complication of anorectal surgery. Severe anal stenosis is a challenging condition. Case Presentation. A 70-year-old Japanese man presented with a ten-hour history of continuous anal pain due to incarcerated hemorrhoids. He had a history of reducible internal hemorrhoids and was followed for 10 years. He had a fever and nonreducible internal hemorrhoids surrounding necrotic soft tissues. He was diagnosed as Fournier's gangrene and treated with debridement and diverting colostomy. He needed temporary continuous renal replacement therapy and was discharged on postoperative day 39. After four months, severe anal stenosis was found on physical examination, and total colonoscopy showed a complete anal stricture. The patient was brought to the operating room and underwent colostomy closure and anoplasty. He recovered without any complications. Conclusion. We present a first patient with a complete anal stricture after diverting colostomy treated with anoplasty and stoma closure. This case reminds us of the assessment of distal bowel conduit and might suggest that anoplasty might be considered in the success of the colostomy closure.
\end{abstract}

\section{Background}

Anal stenosis is a serious complication of anorectal surgery and can complicate hemorrhoidectomy in up to $5-10 \%$ of patients, particularly patients in whom large areas of anoderm and rectal mucosa from the lining of the anal canal are denuded $[1,2]$. It can also occur after other anorectal surgical procedures [1-3].

Treatment, both medical and surgical, should be decided based on severity of the stenosis [1-3]. For severe anal stenosis, one should consider surgical interventions including anoplasty [1-4]. Various types of anal stenosis have been reported, but there are no previous reports of a complete anal stricture. We present a patient with a complete anal stricture after diverting colostomy for Fournier's gangrene.

\section{Case Presentation}

A 70-year-old Japanese man presented with a ten-hour history of continuous anal pain due to incarcerated hemorrhoids. He had a history of reducible internal hemorrhoids and was followed for 10 years. His weight was $70 \mathrm{~kg}$ and BMI $26 \mathrm{~kg} / \mathrm{m}^{2}$. The remainder of the physical examination revealed a fever of $38.3^{\circ} \mathrm{C}$, blood pressure $99 / 67 \mathrm{mmHg}$, HR $142 / \mathrm{min}$, and RR $29 / \mathrm{min}$. The skin of the scrotum was dark red and associated with subcutaneous emphysema. Nonreducible internal hemorrhoids were seen (Figure 1(a)). Laboratory results showed white blood cell count 9300/uL (normal range: $3100-8800 / \mathrm{uL}$ ), neutrophils $77.5 \%$ (50-70\%), hematocrit $46 \%$ (normal range: $40-54 \%$ ), platelet count 13.9 $\times 10^{4} / \mathrm{uL}\left(15-35 \times 10^{4} / \mathrm{uL}\right)$, C-reactive protein $4.04 \mathrm{mg} / \mathrm{dL}(0-$ $0.29 \mathrm{mg} / \mathrm{dL})$, blood urea nitrogen $21.2 \mathrm{mg} / \mathrm{dL}(8-22 \mathrm{mg} / \mathrm{dL})$, creatinine $2.86 \mathrm{mg} / \mathrm{dL}(0.61-1.04 \mathrm{mg} / \mathrm{dL})$, sodium $142 \mathrm{mEq} / \mathrm{L}$ (138-146 mEq/L), potassium $3.2 \mathrm{mEq} / \mathrm{L}(3.6-4.9 \mathrm{mEq} / \mathrm{L}), \mathrm{pH}$ 7.399 (7.35-7.45), bicarbonate $14.6 \mathrm{mmol} / \mathrm{L}(22-26 \mathrm{mmol} / \mathrm{L})$, creatinine kinase $6789 \mathrm{U} / \mathrm{L}(60-287 \mathrm{U} / \mathrm{L})$, and lactate $103 \mathrm{mg} / \mathrm{dL}(6.3-18.9 \mathrm{mg} / \mathrm{dL})$. Fournier's gangrene severity index score was 13 . Computed tomography scan of the pelvis showed edema of the perianal soft tissues. The patient was 


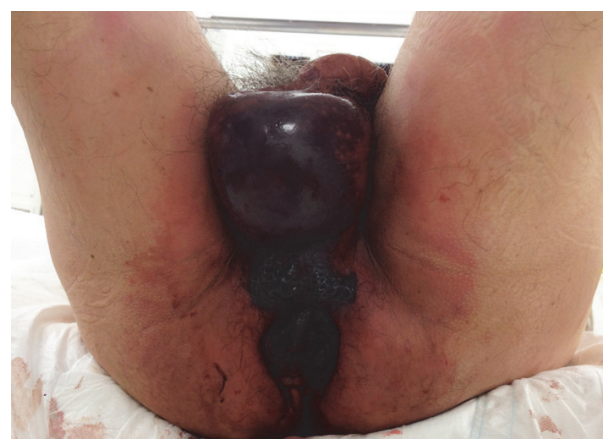

(a)

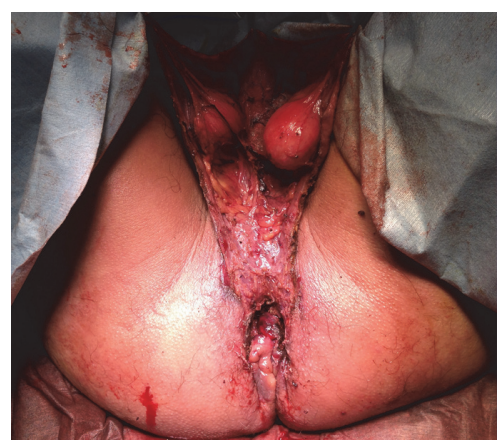

(b)

FIGURE 1: (a) Necrotic incarcerated hemorrhoids and necrotic perineal tissues. (b) Wound after removal of necrotic hemorrhoids and debridement of necrotic tissues.

diagnosed with septic shock due to a necrotizing soft tissue infection secondary to incarcerated hemorrhoids. After fluid resuscitation and antibiotic administration, emergent debridement of necrotic tissues and hemorrhoidectomy were performed (Figure 1(b)). Additional debridement and a diverting loop colostomy were performed two days later. Tissue cultures showed Klebsiella pneumonia and Group $\mathrm{G}$ streptococcus. Renal replacement therapy was used to treat acute kidney injury, but he gradually improved, and his kidney function normalized. He was discharged on postoperative day 39 .

After four months, we planned to perform a colostomy closure. Severe anal stenosis was found on physical examination, and total colonoscopy was performed before surgery, which showed a complete anal stricture (Figure 2). The patient was brought to the operating room and underwent colostomy closure and anoplasty (V-Y flap). During followup, anal stenosis was seen on rectal examination, but the patient did not have significant symptoms. One year later, he appeared fully recovered with no complications.

\section{Discussion}

Anal stricture is a tight narrowing of the anal canal that may interfere with defecation $[2,4]$. The most common cause of an anal stricture is iatrogenic, from excision of anoderm during surgery for hemorrhoids, anal warts, or fistulae-inano $[2,4]$. Anal strictures are usually diagnosed based on a history of difficult or painful bowel movements. Suspicion of anal stenosis is heightened by a history of hemorrhoidectomy, Crohn's disease, or laxative abuse $[2,4]$. The diagnosis of anal stenosis is usually made based on a complete history and physical examination. It is difficult to diagnose anal stenosis in patients who have a diverting stoma because they do not pass stool through the anus and thus have no anal symptoms.

Fournier's gangrene has been reported after treatment of hemorrhoids but complete anal stricture after the treatment of Fournier's gangrene has not previously been reported. Aggressive and repeated debridement is the most crucial step in the treatment of a patient with Fournier's gangrene [5]. Although a diverting stoma can help promote wound healing by avoiding fecal contamination, it should be performed only

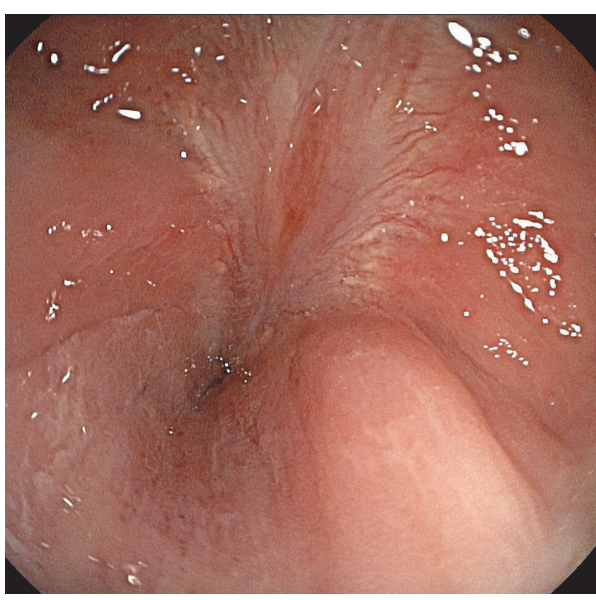

FIGURE 2: Colonoscopy: total stenosis with scarring.

in selected cases, such as Fournier's gangrene involving the anorectal area and sphincter, because stomas are associated with increased morbidity [5].

In the present patient, a complete anal stricture developed in association with debridement and diverting colostomy. Stoma closure was planned, and during preoperative workup, a complete anal stricture was found. Therefore, it was considered necessary to perform stoma closure and anoplasty at the same time.

To prevent anal stenosis, surgeons should avoid excessive excision of normal anoderm. However, in patients with Fournier's gangrene this may be difficult to avoid as wide debridement is essential. After anorectal procedures, a meticulous rectal examination is essential to diagnose anal stenosis early, especially in high-risk patients. Additionally, malignancy should be ruled out in the remaining bowel prior to stoma closure [5].

In summary, this is the first report of a complete anal stricture after treatment of Fournier's gangrene with debridement and a diverting colostomy. This case reminds us of the assessment of distal bowel conduit and suggests that anoplasty might be considered in patients with severe anal stenosis undergoing stoma closure. 


\section{Additional Points}

Institutional Review Board Statement. This report is a case report and does not need a review of IRB.

Biostatistics Statement. There is no statistical analysis.

\section{Data Access}

No additional data are available.

\section{Consent}

The authors have gotten a written informed consent from the patient.

\section{Competing Interests}

The authors have no financial relationships to disclose.

\section{Authors' Contributions}

Dr. Kenji Okumura and Dr. Tadao Kubota designed and performed the research and wrote the paper; Prof. Alan Kawarai Lefor wrote and supervised the report; Dr. Kazuhiro Nishida and Dr. Ken Mizokami provided clinical advice and supervised the report.

\section{Acknowledgments}

Prof. Alan Kawarai Lefor, who is a native English speaker, has been checked all the manuscript.

\section{References}

[1] H. Liberman and A. G. Thorson, "Anal stenosis," American Journal of Surgery, vol. 179, no. 4, pp. 325-329, 2000.

[2] G. Brisinda, S. Vanella, F. Cadeddu et al., "Surgical treatment of anal stenosis," World Journal of Gastroenterology, vol. 15, no. 16, pp. 1921-1928, 2009.

[3] G. Brisinda, "How to treat haemorrhoids," $B M J$, vol. 321, no. 7261, pp. 582-583, 2000.

[4] M. V. Katdare and R. Ricciardi, "Anal stenosis," Surgical Clinics of North America, vol. 90, no. 1, pp. 137-145, 2010.

[5] H. Yanar, K. Taviloglu, C. Ertekin et al., "Fournier's gangrene: risk factors and strategies for management," World Journal of Surgery, vol. 30, no. 9, pp. 1750-1754, 2006. 


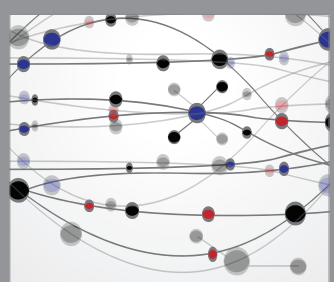

The Scientific World Journal
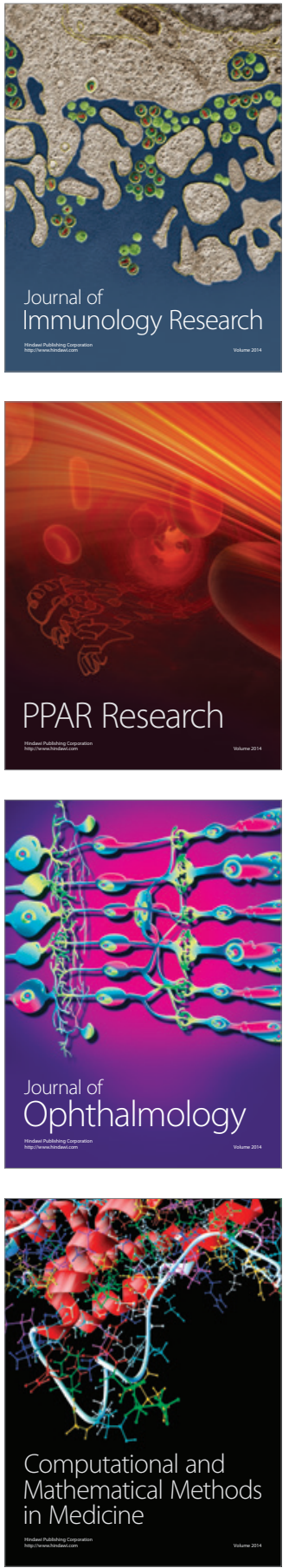

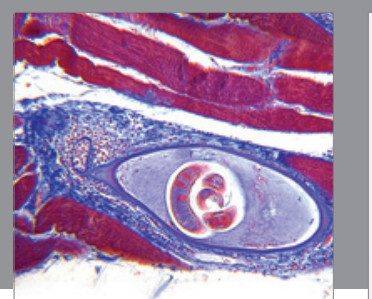

Gastroenterology Research and Practice
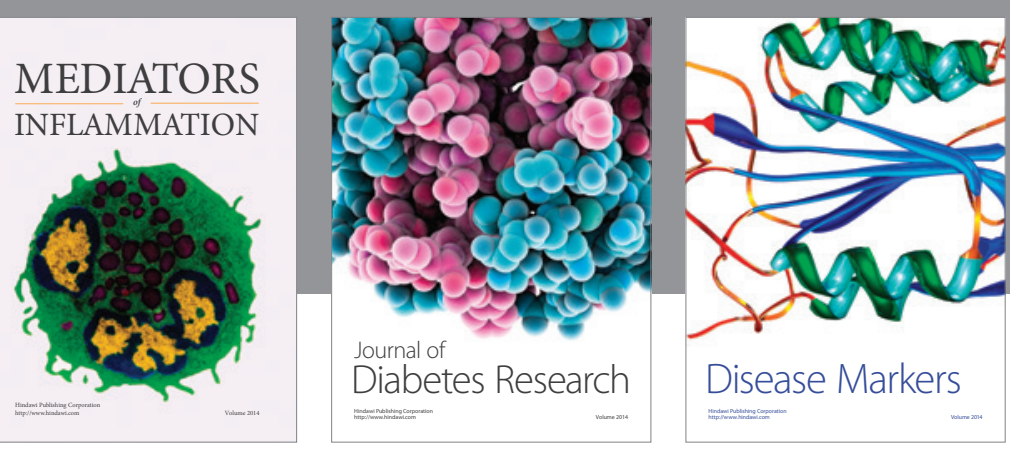

Disease Markers

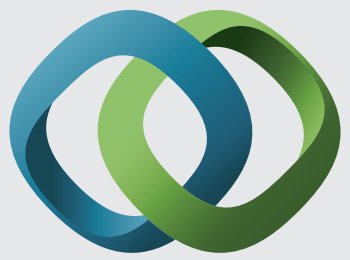

\section{Hindawi}

Submit your manuscripts at

https://www.hindawi.com
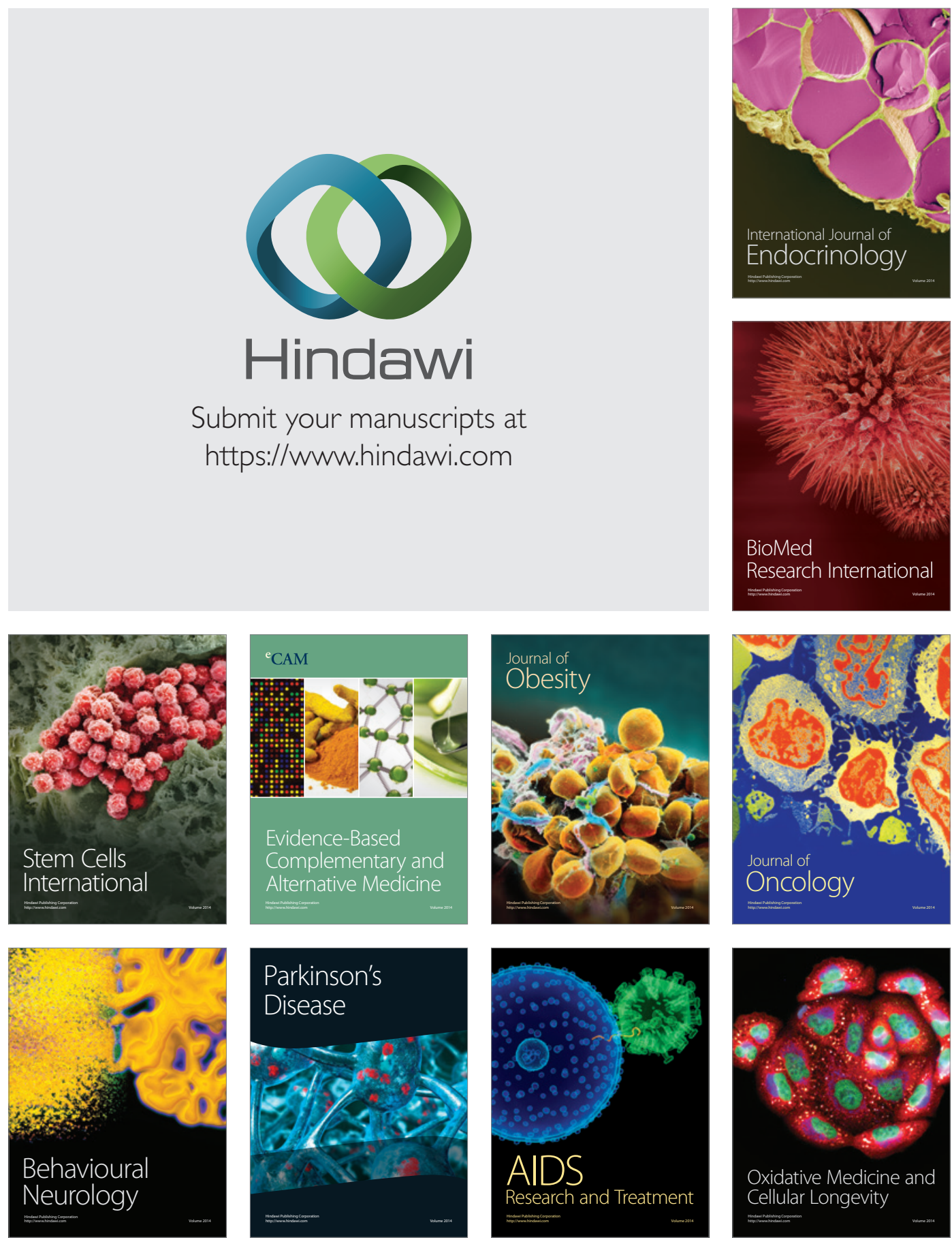